\title{
ERINA, EL LLANTO POR EL PARAÍSO PERDIDO
}

\author{
M. ${ }^{a}$ Teresa Mayor FerRándiz \\ IES «Josep Iborra», \\ Benissa (Alicante)
}

\section{RESUMEN}

Erina es una poetisa griega del siglo IV a.C., cuyo origen oscila entre las islas de Telos, Rodas o Cos. Su cronología es también insegura, pero hay que descartar las afirmaciones de la Suda que la consideran discípula de Safo (siglos VII-VI a. C.), tal vez por la inmediatez de su lenguaje poético y por el amor que la joven Erina demuestra por su amiga Baúcide. Un amor que algunos autores lo consideran homoerótico, lésbico... pero, a pesar de su ambigüedad los estudiosos parecen moverse entre la duda razonable, a causa de lo mutilado de sus poemas y fragmentos.

La obra más famosa de Erina es «La Rueca». Se ignora las razones de su título. Podemos pensar en dos propuestas:

- La Rueca es el símbolo del mundo femenino, de las ocupaciones cotidianas de las mujeres griegas en el gineceo.

- Una clara alusión a Las Moiras o Parcas, que tejen el Destino de todos los seres humanos y que segaron la corta vida de la joven Baúcide.

En el poema se mezclan el dolor por la amiga muerta en plena juventud con los recuerdos de un tiempo feliz, a pesar de las alusiones a ciertos temores infantiles, como Mormo, una ogresa femenina que se nombraba para asustar a los niños.

Erina (o Erinna) fue una poetisa que vivió hacia mediados del siglo IV a.C. en la isla de Telos (Tilos en griego moderno). Respecto a su origen las 
fuentes antiguas oscilan entre Telos, ya citada, Tenos, Teos, Rodas y Cos, isla famosa por sus médicos (como Hipócrates), algunos de los cuales también escribían poemas. Su cronología es muy insegura. Tal vez se debería considerar su pertenencia a una época prehelenística, descartando las afirmaciones del Suda de que era amiga y discípula de Safo de Lesbos, por el contenido de su poesía, escrita con gran sentimiento y con una «inmediatez que recuerda a Safo" (Lesky, 1985: 670). Otra información de la Suda, que conviene rechazar, es la atribución de que había nacido en Teos, colonia griega del Asia Menor, donde se hablaba dialecto jónico y no dórico, que es el que encontramos en los epigramas y fragmentos de poemas de nuestra sensible poetisa.

Para el profesor Vara Donado (1972:67-86), Erina había nacido en la isla de Telos. Su lenguaje, una variedad dialectal del dorio, poblado de eolismos, es muy similar al de la isla de Cos. Cos y Telos distan entre sí unas 23 millas marinas. El profesor Vara Donado documenta su tesis con algunos recursos lingüísticos empleados por la poetisa que aparecen, también, en la isla de Cos, como la forma eúsan del verbo eimí y el sufijo hipocorístico -inna, que es el mismo diminutivo que aparece en el nombre femenino de Filinna, madre del poeta helenístico Teócrito (que había nacido en Cos y había estudiado medicina) y en el nombre propio de nuestra poetisa: Erinna (García Teijeiro, 1988: 818-826; Anglada, 1983: XIV-XV).

Manuel Fernández Galiano (1978: 20) señala que en la ciudad de Teos podría haber nacido su amiga Baúcide y de este dato, también inseguro, habría venido la confusión. Pero en uno de los epigramas dedicados a Baúcide, atribuidos a Erinna (el AP 710), se lee, en el verso séptimo, el adjetivo telio acompañando al sustantivo genos, que se traduce por «origen, nacimiento, familia», etc.

Yo me inclino a creer que la confusión es de tipo fonético: Teos y Telos difieren en muy poco, tan sólo en el sonido «l» (la lambda griega, $\lambda$ ). También podemos hablar de un posible error de los copistas de los manuscritos.

El novelista británico, afincado en Texas, Peter Green, en su novela histórica "Safo de Lesbos. La sonrisa de Afrodita», basándose en la Suda, hace decir a la propia protagonista, Safo, que algunas muchachas que acuden a su escuela:

Quizá incluso, como Erina y Damófila, para atrapar la chispa de mi inspiración y convertirse ellas mismas en poetas

(Green, 1996: 256).

O sea, tradiciones y errores que se han ido transmitiendo de generación en generación y de una época a otra, y que ya han sido cuestionadas. Pero algunas afirmaciones de la Suda son comúnmente aceptadas, como las que ase- 
guran que murió joven y soltera. Datos que se confirman en el epigrama que le dedicó Leónidas de Tarento (¿315-250 a.C.?) compuesto imitando su peculiar estilo:

A Erina, la abeja virgínea que flores libaba,

de las Musas, la más joven de los poetas,

Plutón la raptó como esposa. Razón tuvo en vida

la niña al decir: "envidioso eres, Hades»

(Antología Palatina, VII, 13: 114).

Leónidas de Tarento la compara con la laboriosa abeja, el único animal que, en el cruel yambo misógino de Semónides de Amorgos, es el origen de una clase de mujer trabajadora, llena de divina gracia, callada, poco amante de cotilleos mujeriles, buena y prudente (versos 84-95) y que contrasta con todas las demás, la inmensa mayoría, que vienen a ser, para los varones «la cosa más mala que Zeus hizo".

También Asclepíades nos informa de la temprana muerte de la poetisa:

Mira los dulces trabajos de Erina, no extensos,

Como cuadra a una joven de diecinueve años,

Mas mejores que la obra de muchos ¿Cúal fuera su fama

Si no le hubiera el Hades llegado tan de prisa?

(Antología Palatina, I, VII, 11: 132).

La edad de 19 años, que le atribuye, entre otros, Albin Lesky (1985: 670), procede de confundir la muerte de Erina con la de su amiga íntima Baúcide, dato que aparece en el verso 37 del Fragmento conservado de su célebre poema «La Rueca»: Enea kai dékatos.

Su obra es escasa y mutilada. Pero, aún así, los pocos versos que nos han llegado son muy hermosos, como lo atestigua Antípatro de Tesalónica:

Pocos fueron los versos de Erina y no muchas sus obras,

Mas del corto poema gustaron las Musas

$Y$ así su recuerdo perdura y no queda escondido

Bajo el ala oscura de la negra noche

Mientras a miles y miles de nuevos poetas

El olvido en montón, ; oh amigo!, nos consume.

Mejor es el cisne y su efímero canto que el grajo

Llenando de graznidos las nubes del cielo

(Antología Palatina, I, VII, 713: 345). 
Erina murió virgen, toda su vida fue una «ninfe», palabra que designa una fase intermedia entre el estado de hija y el de esposa, mujer que, en la antigua Grecia, centraba su sexualidad en la reproducción, en el deseo de ser madre. Maternidad que tenía muchos riesgos. Podía ocasionar la muerte de la mujer. El helenista José Vara Donado afirma que Erina murió soltera. En palabras del poeta Leónidas de Tarento, como una «virginal abeja». ¿ Por qué ? tal vez porque la poetisa viera en el matrimonio una amenaza real y cruel, la causa de la separación y posterior muerte de su amada amiga Baúcide, quien podría haber muerto de parto, o de fiebres puerpuerales, una de las causas más frecuentes de mortalidad femenina (Del Barrio Vega, 1992 : 30-31 y 193-199). El ya citado Leónidas de Tarento escribe un interesante poema en el que se imagina un diálogo fantasmal entre un anónimo viajero y una joven esposa muerta, que ha fallecido al dar a luz:

- ¿Quién eres, mujer que aqui yaces y quién fue tu padre?

-Praxo, hija de Calítenes - ¿De qué patria? -Samia.

- ¿Quién te enterró? — Fue Teócrito, el cual recibiome

de mis padres. - ¿ De qué moriste? -Estando encinta.

- ¿Cuántos años llegaste a cumplir? --Veintidós. — ¿Y quedaste

sin hijos? - A Calíteles dejé con tres años.

Pues al menos él viva y que llegue a una edad avanzada.

-Y que todo lo bueno te deje a ti Fortuna.

(Antología Palatina, I: 103-104).

Antípatro de Tesalónica (siglo I a C.) imita fielmente, copiando casi palabra por palabra, este mismo poema (Antología Palatina, I: 364) .

En algunas ciudades griegas, como la belicista Esparta, según Plutarco (Licurgo, 27,2-4), las mujeres que fallecían al dar a luz eran enterradas envueltas en mantos de color rojo escarlata, el símbolo del orgullo espartano, rodeadas de hojas de olivo y en medio de cánticos de alabanza, en una ceremonia semejante a la reservada a los valientes guerreros muertos en combate. Como señala la profesora Ana Iriarte, citando a Nicole Loraux: «El acto de dar a luz es concebido como un combate en defensa de la ciudad a partir del momento en que el vocabulario que traduce el sufrimiento de la parturienta sirve igualmente para expresar el dolcr de los heridos en el campo de batalla" (Iriarte, 1996: 126). Medea, la heroína trágica de origen bárbaro, en la larga lista de reproches que echa en cara a su infiel y desagradecido esposo, Jasón, y a todo el género masculino en general, afirma contundentemente:

Dicen que vivimos en una casa exenta de peligros, mientras ellos luchan con la lanza, iNecios! Prefería estar a pie firme con un escudo que dar a luz una sola vez

(Versos 230-266). 
La obra más famosa de Erina es el largo poema titulado «La Rueca», formado por 300 versos hexámetros, de los que, desgraciadamente, se conservan 54 , todos incompletos: los 14 primeros con palabras y fragmentos de palabras de la parte final del verso; otros 20, con palabras en la mitad del verso; y otros 20, con sólo el principio del verso (Bernabé Pajares, 1994 : 142).

Los filólogos, con mucha paciencia y mayor imaginación, han intentado reconstruir la parte intermedia, la mejor conservada del poema.

Se ignora la razón de su título, «La Rueca», pero podemos pensar en dos propuestas:

a) La rueca es el símbolo del mundo femenino, de las ocupaciones cotidianas que desempeñan las mujeres griegas y algunos varones no griegos, como los egipcios (Heródoto, II, 35), día tras día, en la casa familiar (oikia). Pensemos en la mítica Penélope. Si nos remontamos a las tablillas micénicas, para la tarea de hilar, no encontramos ninguna fórmula lingüística masculina que nos indique que el hombre hilaba, tan sólo la forma femenina «A-RA-KA-TE-JA» (arakateia / alakateia), de la que puede derivar la palabra «elakáte», «rueca, huso» (Alvaro Giner, 1996: 111). Por otra parte, en las tareas de hilar y tejer se reflejan todas las características de los trabajos típicamente femeninos: la trabajadora no debía estar lejos de su hogar. A veces el trabajo se realizaba en el "gineceo». La ocupación era monótona y repetitiva. Para realizarla no se requería gran preparación, ya que no necesitaba mucha concentración. Era apropiada para que la pudieran desempeñar personas analfabetas, como muchísimas mujeres griegas. Era compaginada con otros quehaceres porque es un trabajo que se podía interrumpir constantemente para atender otras faenas domésticas (como cuidar niños pequeños, darles de mamar, cocinar, limpiar, acarrear agua desde la fuente más próxima a la vivienda, etc) y se podía retomar sin ningún problema. No era un trabajo peligroso, pero sí aburrido, debido a su constante monotonía, que era rota con canciones, chismes, cotilleos y relatos mitológicos. No requería fuerza física, pero sí paciencia, una tópica virtud femenina. No estaba pagado, o lo estaba insuficientemente, etc . En el poema de Erina es la madre quien reparte la lana entre las criadas para que la trabajen (versos 23-24).

b) Una clara alusión a las Moiras o Parcas, que cortaron la vida de la joven Baúcide en la flor de su juventud. $Y$ es que las imágenes del mito pueden servir para explicar, simbolizar, expresar ideas y proporcionar referencias. Las Moiras son tres hermanas divinas que personifican el Destino (en griego «moira») de todos los seres humanos. A su imnenso 
poder están sometidos los propios dioses olímpicos, como podemos ver en los versos 99-104 de la tragedia las Bacantes de Eurípides:

(Zeus) lo dio a luz, cuando las Moiras cumplieron el plazo, al dios de cuernos de oro. Y lo coronó con coronas de serpientes.

Sus nombres son: Cloto, la «hilandera», Láquesis, «La que da a cada uno su lote», y Átropo, la «inflexible». Se las representa iconográficamente como a mujeres ancianas hilando y tejiendo. El hilo que manipulan es el «hilo de la vida» y el destino de cada ser humano individual. Cuando un hilo se rompe, o es cortado por Átropo, significa que la vida de esta persona ha tocado a su fin. El poeta Hesíodo, en los versos 217 y siguientes de su Teogonía, las hace hijas de la Noche sola, pero en el verso 904 aparecen como hijas de Zeus y Temis, divinidad preolímpica, segunda esposa de Zeus. Apolodoro, en su Biblioteca $(\mathrm{I}, 3,1)$ coincide con esta última genealogía dada por Hesíodo:

Con Temis, hija de Urano, (Zeus) engrendró hijas: las Horas, Eirene, Eumonía y Dike, y las Moiras, Cloto, Láquesis y Átropo.

«La Rueca» es, pues, un poema en pésimo estado de conservación. Sin embargo, su contenido temático no ofrece muchas dudas. Es, sobre todo, un largo y sentido lamento por la amiga muerta, lleno de expresiones puntuales y punzantes de dolor. Albin Lesky afirma que si estuviera escrito en dísticos se podría considerar una elegía (Lesky, 1985: 670).

En el poema, además de la pena por la amada amiga muerta, vemos una sentida añoranza por la infancia perdida, que se convierte en una especie de «paraíso perdido». Un tiempo alegre y feliz en el que Erina compartía con su inseparable Baúcide secretos y juegos infantiles, como el «juego de la tortuga» y «las muñecas». También aparecen los miedos y los temores infantiles, simbolizados en la terrorífica figura de la ogresa Mormo del verso 25.

Mormo era un genio de sexo femenino con el que se amenazaba a los niños y niñas pequeñas para que no desobedecieran a sus padres y se portaran bien. Era el equivalente al «Coco» o al «Hombre del Saco» «de nuestra ya lejana infancia... Era identificada con Gelo, Lamia y Empusa.

Gelo era un fantasma femenino originario de la cercana isla de Lesbos. Era el alma atormentada de una muchacha muerta que había fallecido sin haber tenido hijos y que volvía del más allá para robar a los niños pequeños y llevárselos al tenebroso reino de los muertos, al Hades.

La historia de Lamia era mucho más terrible. Lamia fue una muchacha muy hermosa amada por Zeus. Hera, su celosa y vengativa esposa, cada vez 
que Lamia paría un hijo, lo hacía morir, y Lamia, loca de dolor y desesperación, acabó convirtiéndose en un monstruo insomne que robaba y chupaba la sangre de los niños pequeños. Zeus, finalmente, se compadeció de ella y le concedió el extraño don de quitarse los ojos a voluntad, para poder, así, dormir y descansar, olvidándose de su gran infortunio (Grimal, 1994: 303-304, 312-313; Pedraza, 1983 : 97 ). En la mitología latina las Lamias, en plural, son representadas como mujeres hermosas que, de cintura para abajo, toman la forma de una serpiente, como el hada medieval Melusina.

Empusa era un genio femenino del séquito de la terrible diosa Hécate. Se alimentaba de carne y sangre humana joven. Para atraer a sus inocentes víctimas, adoptaba la fascinante figura de una mujer bellísima. De esta manera las enredaba en las peligrosas redes de una seducción mortal. Empusa es citada por Aristófanes, en el verso 1057 de su comedia «La Asamblea de las Mujeres», cuando el infeliz Joven es raptado por una repugnante vieja, porque la nueva Asamblea de la polis (el mundo al revés) ha decretado una Ley por la que las mujeres más feas, y más ancianas, tienen preferencia, a la hora de mantener relaciones sexuales, sobre las jóvenes y hermosas:

Vieja : No soy yo, sino la Ley, quien te arrastra.

Joven: ¿La Ley? no, a mi no, sino Empusa cubierta de pústulas sanguinolentas.

Filóstrato, escritor tardío, representante de la Segunda Sofística, en el libro II de su «Vida de Apolonio de Tiana», nos cuenta que a su biografiado personaje (un curioso individuo, mezcla de brujo, taumaturgo y filósofo), una noche de luna llena, se le aparece una Empusa. Apolonio se percibió de su presencia $\mathrm{y}$ :

Se puso a insultar a la "Empusa" él mismo y encargó a los que iban con él que hicieran lo mismo, pues éste es el remedio contra tal irrupción . La aparición se dio a la fuga chillando como los fantasmas (II, 4).

En el libro IV el propio Apolonio de Tiana desenmascara, en la ciudad de Corinto, a otra «Empusa», para evitar que el joven Menipo de Licia, un hermoso atleta de noble estirpe y veinticinco años de edad, caiga en sus seductoras redes. La «Empusa» de Corinto aparece como una mujer fenicia muy rica, bella, elegante y enamorada del joven Menipo, a quien le ofrece sus aparentes riqueza y amor. Pero Apolonio de Tiana le hace ver al muchacho la falsedad de todos los objetos de oro y plata: 
Pensad eso de esta ornamentación. Pues no es materia, sino apariencia de materia. Y para que sepais lo que quiero decir, la buena novia es una de las empusas, a las que la gente considera lamias o mormolicias. Esas pueden amar, y aman los placeres carnales, pero sobre todo la carne humana, y seducen con los placeres sexuales a quienen desean devorar.

Y, finalmente, acaba por desenmascarar a la falsa mujer:

Al insistir Apolonio y no dejarla escapar, reconoció que era una empusa y que cebaba a Menipo con vistas a devorar su cuerpo, pues acostumbraba a comer cuerpos hermosos y jóvenes porque la sangre de éstos era pura $(I I, 4$ y $I, 25)$.

Este relato fantástico de Filostrato sirvió de inspiración a Goethe para su balada La Novia de Corinto, escrita alrededor del año 1799, una alegoría narrativa llena de fuerte sentido simbólico.

La mayoría de los genios maléficos de la mitología griega eran monstruos femeninos: Empusa, Lamia, Gelo y Mormo. Estas ogresas, de carácter fantasmal o infernal, para Jean-Pierre Vernant, "expresan en el mundo de los niños lo que representa Gorgo para los adultos». Quieren la muerte de los niños, su sangre. Son seres que están «emparentados con la muerte, pertenecen a su reino aunque caminan con los vivos "(Vernant, 1986: 82-83). Como los vampiros. Vienen a ser unos claros antecedentes, míticos y literarios, de la turbadora vampira lésbica Carmila, fascinante criatura que protagoniza la novela de Sheridan le Fanu que lleva como título el nombre de este seductor ser de ultratumba.

Sin embargo en el mutilado poema de Erina, La Rueca, es el anónimo esposo de Baúcide el portador de la desgracia y de la pena para la poetisa. Él es el auténtico «enviado de Mormo», quien le arrebata la persona amada, que no es otra que Baúcide.

Nos podemos imaginar una relación triangular parecida a la que se puede ver en el Fragmento 31 de Safo. Aquí los implicados en el triángulo amoroso son:

- Baúcide, la amiga entrañable.

- Erina, la poetisa, que evoca, con dolor y desesperación (una desesperación fronteriza con la hybris), un pasado que no volverá más y que añora como se añoran los paraísos perdidos.

- Y el marido, el rival amoroso, cuyo nombre ignoramos, que aparece como la amenaza real y física, no como la mítica Ogresa de ficción, pues es él quien se interpone entre las dos inseparables amigas: 
Más cuando llegaste al lecho de un varón, te olvidaste de todo, Cuando oiste en tu infancia y entonces, en casa de mi madre, Querida Baúcide, Afrodita puso olvido en tu mente.

En la Grecia clásica el matrimonio era un contrato entre el padre de la novia y su futuro esposo, lo que venía a significar un traspaso del derecho de tutela sobre la muchacha. El acto por el que dicho contrato cobraba valor legal era la entrega de una dote. Este hecho es lo que establecía una notable diferencia entre el matrimonio legítimo y el simple concubinato. La edad media para contraer matrimonio era de 14-15 años para las mujeres y de 30 para los varones, que era la edad exigida para que los hombres ejercieran su derecho como ciudadanos.

El ciudadano ateniense (polítes) es definido por Aristóteles como el que sabe obedecer y mandar (Política, III, 1275 a). Las mujeres están excluídas. No asisten a las Asambleas. Son unas eternas menores de edad, siempre tuteladas por los varones. Son, en la práctica cotidiana, unas no ciudadanas que, sin embargo, transmiten a sus hijos varones unos derechos y unas condiciones de vida que ellas no disfrutaban en absoluto. De ahí la importancia de la maternidad.

Volviendo al poema de Erina, se puede establecer otro paralelismo entre La Rueca y el Fragmento 94 de Safo, donde la poetisa de Lesbos desea morir porque su amiga la ha dejado contra sus deseos. Tan sólo le queda añorar el pasado feliz, como Erina, los momentos compartidos que disfrutaron juntas trenzando coronas de violetas y otras flores de exquisito perfume.

En La Rueca Erina nos habla, además, de su lamento por no poder ver el cadáver de su amiga, tal vez porque Baúcide había fallecido lejos de Telos, en otra isla o en otra ciudad (¿Teos?). En este sentido podemos traer, aquí, otro de los pocos fragmentos poéticos conservados. Está formado por dos versos. No sabemos si pertenecen o no a La Rueca. La duda se impone:

Pez piloto, que escoltas la navegación de feliz curso de los marinos

Da escolta a mi dulce amiga desde popa.

A Simónides de Ceos (557-468 a. C.) se le atribuye este epigrama funerario dedicado a los heroicos hoplitas espartiatas muertos en el Paso de las Termópilas (480 a. C.):

Extranjero, anuncia a los Lacedemonios que aquí Yacemos, obedeciendo las órdenes que nos dieron (García Gual, 1989: 102)

También Erina, como Simónides, emplea en sus epigramas funerarios las figuras literarias conocidas como personificación e invocación: 
Estelas, sirenas mías, y lamentable urna

Que para Hades guardas un poco de ceniza.

Decid adiós a quienes pasen por mi tumba,

Conciudadanos o de otra ciudad,

Y que esta sepultura me guarde a mí recién casada,

$Y$ que mi padre me llamaba Baúcide, que soy de origen

Telio, para que lo sepan, y que mi compañera

Erina grabó en mi tumba este epitafio.

La influencia de Simónides de Ceos es evidente.

¿Es el amor de Erina por Baúcide un amor lésbico? Para Alberto Bernabé Pajares (1994:146), traductor y estudioso de su fragmentaria obra, no hay la menor duda: «Efectivamente Erina enlaza con el mundo femenino y privado de Safo, especialmente en el tema del amor sentido por otra mujer». El profesor Rodríguez Adrados (1995:101) es más cauto y más prudente cuando escribe que: «Fuera de Lesbos, quizá los versos melancólicos de Erina a su amiga Baucis muerta en Telos, en el siglo IV a.C, tengan alguna relación con este ambiente, pero no es seguro". Y, finalmente, Juan Francisco Martos Montiel (1996:48), en su libro Desde Lesbos con amor: Homosexualidad femenina en la Antigüedad, parece moverse entre la duda razonable (pues los escasos versos conservados de Erina no nos permiten averiguar sus preferencias eróticas) y la atribución de tendencias lesbianas a nuestra poetisa, cuando afirma, citando a S. Bernard, que «Erina era: Lesbiana en el sentido moderno, si no física al menos psicológicamente».

\section{REFERENCIAS BIBLIOGRÁFICAS}

Alfaro Giner, C. (1996): «Aspectos del trabajo femenino en el mundo antiguo». En Actas del IX Congreso Español de Estudios Clásicos, 1, 109-113. Madrid : Clásicas.

ANGLADA, M.A. (1983): Les germanes de Safo. Antologia de poetes hel.lenístiques. Barcelona : Edhasa.

Bernabe Pajares, A. y Rodriguez Somolinos, H. (1994): Poetisas griegas. Madrid: Clásicas.

Del BARRIO VeGA. M.L. (1992): Epigramas funerarios griegos. Madrid: Gredos. Fernández-Galiano, M. (1978): Antología Palatina, I. Madrid: Gredos.

Fernández URiel, P. y VÁzquez Hoys. A. M. (1994): Diccionario del mundo antiguo. Madrid: Alianza.

GarCia Gual, C. (1989): Antología de la poesía lírica griega. Siglos VII-IV. Madrid: Alianza. 
- (1996): «Jasón, el héroe que perdió el final feliz». En Mitos, viajes, héroes, 113-170. Madrid: Alfaguara.

García TeiJeiro, M. (1988): «Los poetas bucólicos». En Historia de la Literatura griega. J.A. LÓPEZ FÉrEZ (Ed.), 817-828. Madrid: Cátedra.

Green, P. (1996): Safo de Lesbos. La sonrisa de Afrodita. Barcelona: Edhasa.

Grimal, P. (1994): Diccionario de mitología griegas y romana. Barcelona: Paidós.

IRIARTE, A: (1996): «Ciudadanía femenina y procreación en la Atenas clásica». En Actas del IX Congreso Español De Estudios Clásicos, I, 123-126. Madrid : Clásicas.

LESKY, A. (1985): Historia de la literatura griega. Madrid: Gredos.

MARTOS MONTIEL, J.F. (1996): Desde Lesbos con amor: homosexualidad femenina en la Antigüedad Madrid: Clásicas.

Pedraza, P. (1983): La Bella, enigma y pesadilla (Esfinge, Medusa, Pantera). Valencia: Almudín.

Rodríguez Adrados. F. (1995): Sociedad, amor y poesía en la Grecia antigua. Madrid: Alianza.

VARA Donado, J. (1972): «Notas sobre Erina». Estudios Clásicos, 16, 67-86.

VERNANT, J. P. (1986): La muerte en los ojos. Figuras del Otro en la antigua Grecia. Barcelona: Gedisa. 